\title{
Analyzing The Women's Role In Engineering And Science
}

\author{
M. Sadiq Ali Khan \\ Department of Computer Science \\ University of Karachi \\ Muhammad Nadeemullah \\ Department of Social Work \\ University of Karachi \\ Ghazal Khwaja Humayyun Akhtar \\ Department of Public Administration \\ University of Karachi
}

\begin{abstract}
A women's career till middle of the $20^{\text {th }}$ century was not more than a school teacher, a librarian, a social worker or a nurse. A woman really had to work hard to earn less pay for the same job where men are highly paid, in this male-dominating society. The birth of Computer age opens the door of a whole new type of career for women: programming; the process of enabling machines to do a certain task by writing a set of instructions. Historically and conventionally, presence of women associated with field of engineering and science have been less prominent as compared to their counterpart. However, recent efforts initiated through various organizations, governmental and nongovernmental, attempting development of interest, promoting significance, increasing awareness and creating opportunities have improved statistics considerably. Globally, involvement of women with engineering and science has always been noticeably low. In this research article, we analyze the role of women in engineering and science, specially the science of information technology discipline and highlighting the causes of women's experience and work role in a male dominating environment.
\end{abstract}

\section{تلضيصِ}

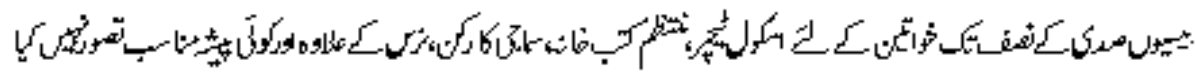

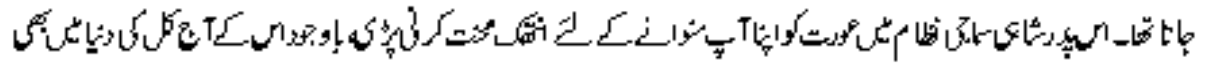

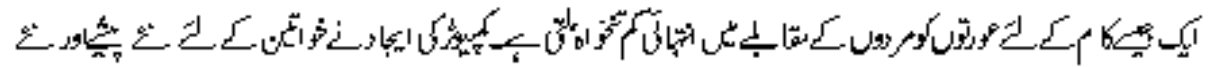

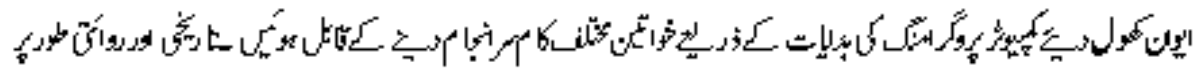

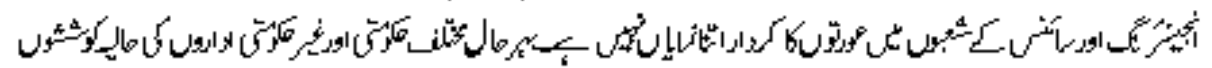

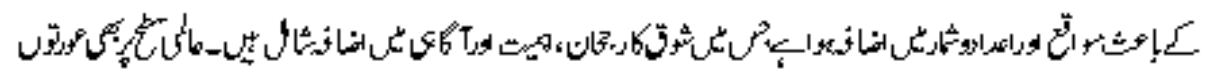

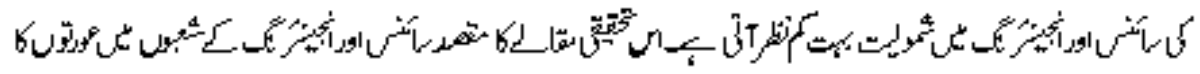

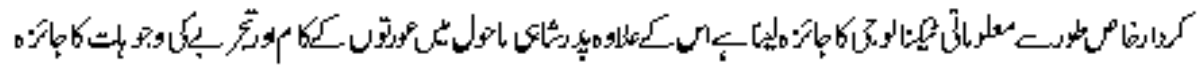
$\leftarrow$ 
Key Words: Women's Role, Engineering, Science.

\section{Introduction}

Globally, involvement of women with engineering and science has always been noticeably low. Considering the causes that influence such behavior and study the reasons which are somewhat similar worldwide. Professions like education, history, languages, and humanities with the exception of medical sciences to some extent, have always been the fields of concentration for females. Examining the reasons and explanations discloses that logics rationalizing the reduced participation in engineering and science are generally obnoxious.

Pointing out most common explanation, that effects the situation, and most popular justification would be environmental and social factors revolving around women. Another popular excuse for lack of interest is consideration of the women's physiological inability to succeed as engineers (Richard, 2005). Negative perceptions regarding female engineers, stemming from both men and women, has been playing as a significant factor in explaining their low numbers within the field. Discrimination of employers while hiring female scientists and engineers also play a huge part in this dilemma (Pearl, Amy et.al. 1990). Comparatively speaking engineering disciplines tend to be less attractive for females, most probably because of the conditions surrounding the technologies. Some of the disciplines such as mechanical, civil, industrial, automotive engineering simply will not accommodate feminine behavior. Throughout the educational phase and professional life, individuals need to be involved with vigorous physical effort. However, some disciplines like computer, electronics, bio- medical engineering and chemical engineering attract fair share of female intellect.

Science on the other hand receives bigger share since manual labor plays very little role, and inquisitive minds are more comfortable with research and design rather than implementation (Ayse Bugra, 2014). In addition, with science the disciple has an opportunity with staying intact with the discipline through research and further extending the career as an educationist. The worldwide increase in female faculty members corroborates this phenomenon.

Demographics substantiate the fact that, in past decade more women are now joining the fields of engineering and science, however, the gap between the male and female have widened. This is due to the greater increase in number of males joining the same discipline. Until the year 1997, females claimed twenty-two percent placements in engineering and science worldwide (Mark J. Cherry, 2010). The ratio now stands at nineteen percent because greater number of men as compare to women joined the two professional and educational 
classifications. Therefore comparatively speaking, although greater number of women now joins the field of engineering and science, even greater number of men joins the same.

The task can be anything from adding two numbers to building an unmanned autonomous vehicle. Dr. Grace Hopper, a staff scientist in systems programming in Univac and the original coiner of the term "debugging", explained: "You have to plan ahead and schedule everything so it's ready when you need it (Weisert, 2014). Programming requires patience and the ability to handle detail. Women are 'naturals' at computer programming. Computer Science is a male-dominated field, where a working woman of this field has to face experiences or challenges that are unique what they face in gender-balanced and female dominated professions. If we talk about the very beginning of this field one can say women were the driving force, in fact, the very first programmers were women. At that time there was an infrequent influx of women and there may have been many reasons for this. May be as computer industry rises for the first time in general so there was a need of workers with aptitude or in some measures programming was not yet defined as engineering field and women thought that some programming work could be done at home.

\section{Background}

Women programmers at that time were well-paid professionals who worked side by side with male colleagues. The thought that writing code is indeed a challenge like mathematics, chess and other stereotypically male activities initiated to compel women to left for other things. As, the hardware side includes clerical work and a general assumption is that designing hardware includes heavy-lifting so this side is already reserved for male engineers. From here the percentage of women in Computer Science field began to fall and Computer Science, the backbone of any technology start-up, became a male dominated field. The percentage of women with Computer Science as their major was 37\% in 1984 (Acdalal, 2011). But from 1984 to 2006 it is dropped from $37 \%$ to $20 \%$. The reason women left Computer Science are as intricate and numerous as why they had entered in the first place (Bart, 2000).

Even efforts are took place to give women more benefits in order to take education in science and engineering, but considerably they are in less number in computer science program specially. The number of percentage in science and engineering workforce is decreasing in major counties.

- Inequality in opportunity: In all the fields actively engaged in technology and innovation such as property, financing and education, women have less access to resources. As a result, their presence in employment and entrepreneurship is lower than men.

- Interest and participation in other fields of science. Females show greater interest in biological and medical related field comparative to mathematical or computational field. 
- Contributions to decision making, In universities, Women have low rates (about $12 \%$ ) of participation in decision-making in science.

- Other responsibilities, almost $30 \%$ of women who enroll themselves in technology programs drop out due to lack of flexible work hours and child care.

- Surviving in a male dominating environment: Many of the women do not apply for jobs because they think there would be less number of women in the offices and they do not feel comfortable to work in a male dominating environment.

Gender equality is not just about economic empowerment. It is a moral imperative, it is about fairness and equity, and includes many political, social and cultural dimensions. Gender equality, however, is also a key factor in self-reported well-being and happiness across the world (Justin T Denney et.al. 2013).

Despite all these things, the trend is beginning to reverse itself. According to a report by National Center for Women \& Information Technology (NCWIT) in June 30, 2013, here are some demographic on technical women which shows women are playing active role in I.T and Computer Science: Women comprises 20\% of web manager; 25\% programmers; $30 \%$ database administrator; $15 \%$ software engineer; very few hold a position of CEO/CIO at different companies. Successful start-ups have twice as many women in senior roles than unsuccessful companies.

Although women are increasing in numbers, their ratio represents lower status in the workplace and remain associated with the conventional carriers (Tinklin et.al, 2005). Income earnings of the women's have been found to increase with their educational level and experiences they have (Day \& Newburger, 2002). Women are less likely to be employed in science and engineering jobs roughly $20 \%$ less their male counterparts (Graham and Smith, 2005)

\section{Results}

Women's representation in Science \& Engineering discipline is generally low as compared to others. As professional women is more participating towards teaching occupation in Science and Engineering discipline, they preferred and love to do the above job. The spirited environment of industry often means that influence for rising women's entrance to Science and Engineering has been based exclusively on industry requirements rather than a move towards comprehensive cultures. The study shows data collected from selected universities of engineering and science in Pakistan. 
Table 1

Undergraduate \& Postgraduate Students in Higher Education

\begin{tabular}{|l|c|c|c|}
\hline & $\begin{array}{c}\text { Total Higher } \\
\text { Education } \\
\text { students }\end{array}$ & $\begin{array}{c}\text { Total } \\
\text { Women }\end{array}$ & \% of Women \\
\hline Medical related subjects & 50490 & 32972.5 & $65 \%$ \\
\hline Physical \& Mathematical Sciences & 125530 & 47910 & $38 \%$ \\
\hline Computer science & 126158 & 75300 & $60 \%$ \\
\hline Engineering \& technology & 142163 & 44454 & $31 \%$ \\
\hline $\begin{array}{l}\text { Average in all Science, Technology \& } \\
\text { Engineering related areas }\end{array}$ & 111086 & 50160 & $45 \%$ \\
\hline $\begin{array}{l}\text { Students in Science, Technology \& } \\
\text { Engineering related areas (\%) }\end{array}$ & $28 \%$ & $22 \%$ & \\
\hline
\end{tabular}

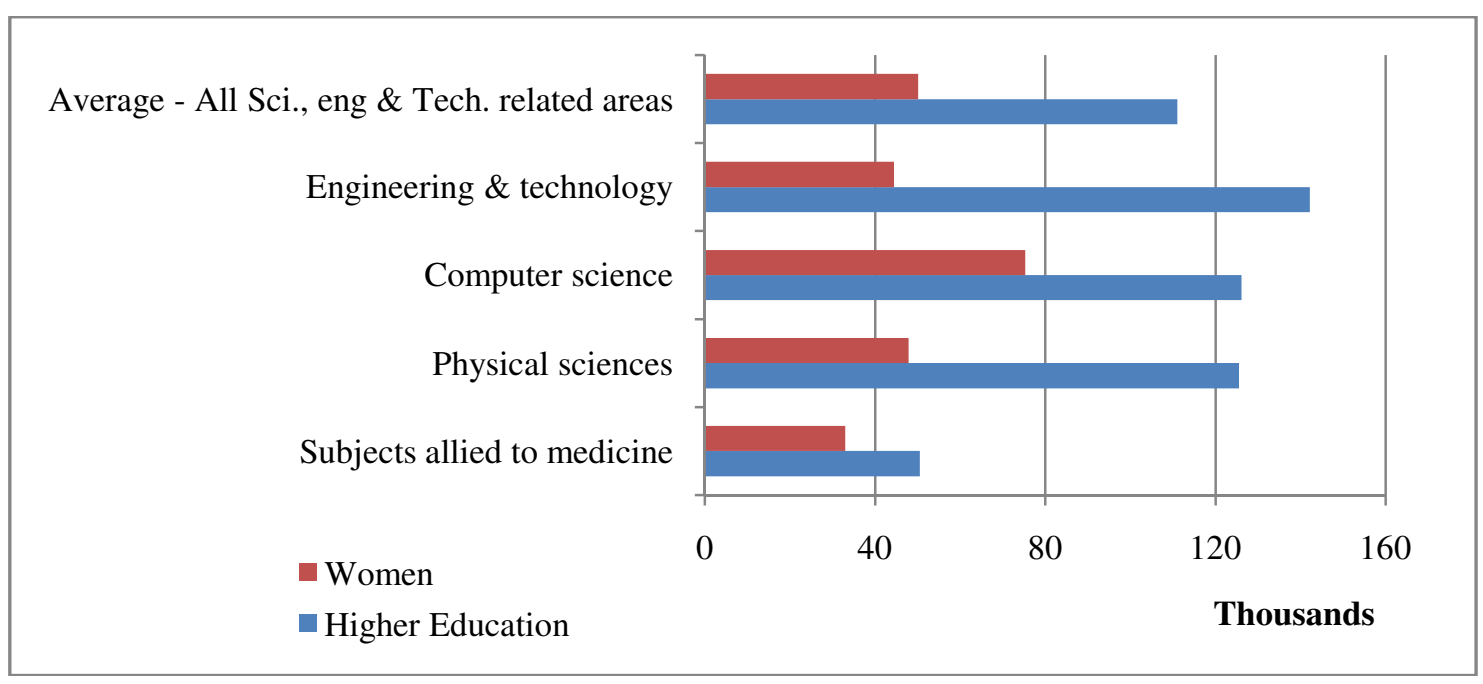

Figure 1: Graphical representation of Higher Education student's with reference to Pakistani society

As Table 1 show that average $60 \%$ women in Computer science at higher education level with respect to Pakistan, 31\% women in Engineering and Technology discipline. From overall students on average in science, technology and engineering discipline, women ratio is increasing and going better i.e 22\% (Table 1). Figure 1 shows the graphical representation of the higher education students, collected through surveys with respect to Pakistani society. 
Table 2

Professionals Aged 20-60 in Science, Engineering and ICT

\begin{tabular}{|l|c|c|c|}
\hline & $\begin{array}{c}\text { Total } \\
\text { Professionals }\end{array}$ & $\begin{array}{c}\text { Total } \\
\text { Women }\end{array}$ & $\begin{array}{c}\text { \% of } \\
\text { Women }\end{array}$ \\
\hline Science Professionals & 251688 & 123210 & $49 \%$ \\
\hline ICT Professionals & 656370 & 296753 & $45 \%$ \\
\hline Engineering Professionals & 568652 & 156816 & $28 \%$ \\
\hline $\begin{array}{l}\text { Average all science, engineering \& } \\
\text { ICT }\end{array}$ & 492236.7 & 192259.7 & $39 \%$ \\
\hline
\end{tabular}

In professional carrier women participation in engineering is quite low as compared to other science and technology areas just $28 \%$ as Table 2 shows. Women's interest in ICT profession is increasing day by day (Table 2) as new healthy opportunities waiting for them. In general science professions women's role is quite impressive.

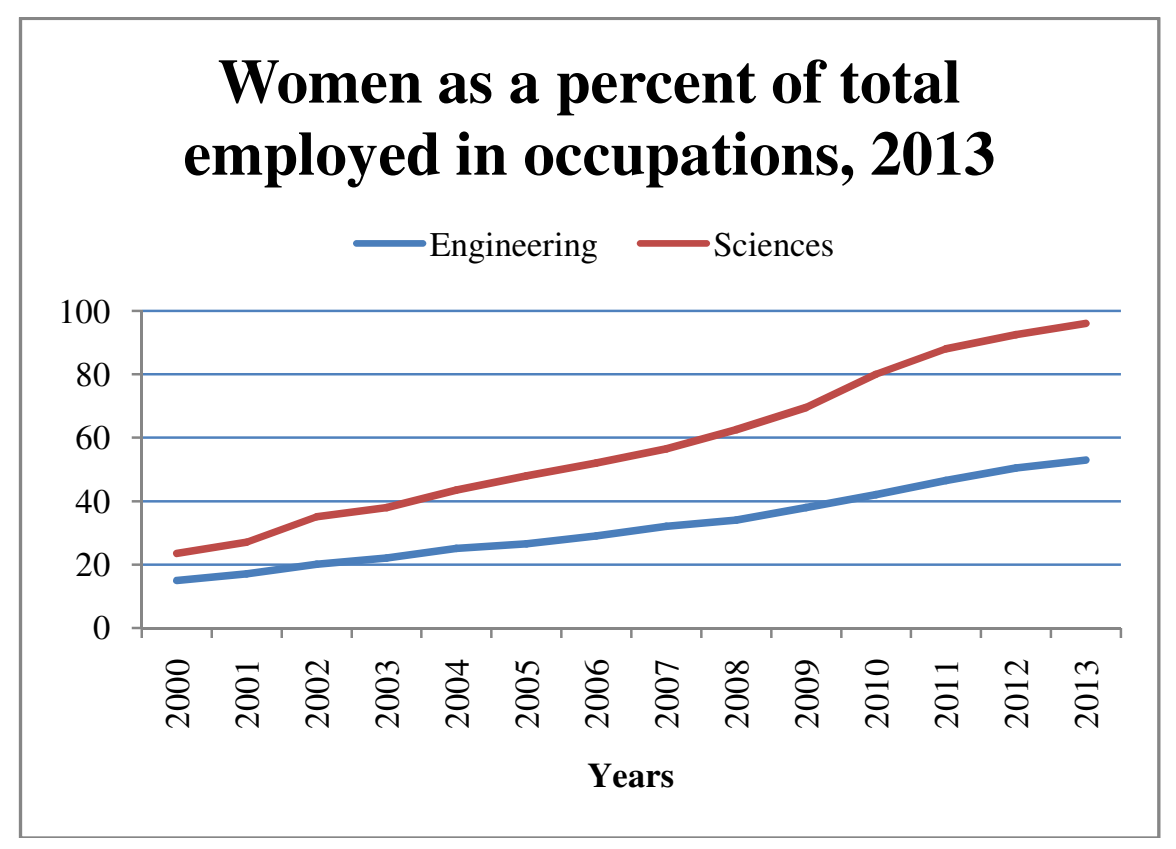

Figure 2: Average \% of total employed woman in Engineering \& Science

Figure 2 shows the average working women in science are much higher than engineering sector. In the past ten year, tremendous changes occur in the women employment sector. Most important thing women are not just taking part in the subject area of sciences; it plays a vital part in the engineering sector. 


\section{Analysis \& Discussion}

Persuasive drives, backed up by opportunities that are more lucrative, therefore, should surface where convincing factors represent not only an optimistic future for the women but also appreciation of their contribution will reflect national interest. Identifying some obstacles that discourage women should help to improve the situation and optimizing process more promising. Governmental and non-governmental should carry out drives pertinent to such propositions, where the interest of women in exploring disciplines of engineering and science enhances. However, regardless of where the initiative comes from, the gender itself must also show concern and intent for participation. Realizing the benefits might help to convince more women, expediently encouraging their active participation.

With stronger correlation between increased women engineering faculty and increased likelihood of female students majoring in engineering and scientific fields, women engineers and scientists have better chances of promoting and creating enthusiasm. Additional meaningful opportunities rendering direct connection with female faculty and more significantly involved in hands-on research under the watchful guidance of female academic mentors will give added advantage. Female engineers may serve community as faculty leaders and as living examples in recruiting women by sharing their own science and engineering beneficial learning experiences. Working as positive change agents and academic leaders recruiting, and mentoring women engineering students, this perspective could help develop unique relationship, which in turn would institute comfort amongst the prospects.

Emphasis towards establishing more institutions catering the fields of engineering and sciences, which accommodate women solely, is also highly recommended. The females while seeking stepping-stone feels more comfortable around an atmosphere where institutional management is under the control of same gender. Societies no matter western or eastern face the dilemma of mutual respect amongst the two genders therefore, the females tend to avoid situations where they feel unsecure and uncomfortable. Educating counterpart to respect and have more considerate attitude towards women will help to ease this predicament.

Cumulatively speaking the share of women in engineering has been lesser than that of science altogether, and even in the field of science, women always been lesser by great proportion. However, throughout the ages there is evidence of female scientists that have claimed their share of fame, by contributing to research and development of technology such as Marie Curie, Maria Mayer and Barbra McClintock, evidence that when situated properly women are quite capable of contributing to the two fields. In the field of engineering given the sincere opportunity, women should be able to perform equally well. 
Another prominent reason that adds to low rate of female engineers includes lack of female engineering role models. Since there are very few female engineering graduates, there is also less role model. Misconceptions of what it is like to be an engineer, and having fewer technical problem-solving opportunities through early life compared to men. Research shows that lack of confidence is a huge factor, especially when competing with men. The blame for this reduced buoyancy lays upon stereotype that links masculinity to engineering and technology is, unfortunately, still prevalent and difficult to overcome.

Suggestively speaking, there is an immediate need for sponge down of the social order globally, if we earnestly want to see increase in active participation of women in the fields of engineering and science. Consortiums and committees should be established where the core agenda should be the change in mind frames of men and women both. Until this mindset reduces from our societies and cultures, the chances of increasing the ratio will most likely not improve.

There is a general belief that women are most likely to draw toward professions that can improve society and individual lives. Young women often comment that they want a career where they can help make things better; this being the case, then engineering should be the ideal career choice. The opportunities are available; however, the awareness is not. Any of these fields of science, technology or engineering will turn in to lucrative career while serving communities.

Women engineers bring unique perspectives to the workplace; with limited diversity, there are limited ideas to bring to the table. Since half the population of our planet is female, and who better than women to realize the machines and technologies that will create an impact on our life style. Men may engineer products and gadgets but women lead the number of users. Considering this factor, women as engineers will contribute in bringing out better products. The diversity in opinion will improve the devices in many aspects. In addition to generally being more collaborative, women have an intuitive sense of usability that leads to better products.

Virtually everything we touch and do every day has had some impact from an engineer, and female gender has a larger say in purchasing these products. Realizing this fact, companies want user interfaces that appeal to all buyers, and this is only possible if both male and female work hand in hand, attempting to create better products. Therefore, female engineers are in demand with educated entrepreneurs investing in engineering of devices. Statistics also reflect women being particularly good at bringing the team together and at presenting, which are extremely important skills when developing a product.

Conclusively speaking for past two decades the awareness programs are now initiating drives to attract women in fields of engineering and science. Overnight turnaround is not expected but one feels some impact, as more women are now joining these two fields. 
However, even though the number of women has increased the ratio of women in comparison to men has declined. Expediting the process by creating opportunities targeting females and creating institutions for the same should release better results in near future.

\section{Conclusions}

Women are under-represented in the IT industry, especially in high-level positions. The belief of men's superiority in the field of technology and the male-dominant working environment inhibit women's involvement in the IT industry. Finally, the thing which greatly decreases women work identity in IT is the conflicts between work and family. All of the married females of I.T department stated that their family greatly influenced their career and if women have to choose between a successful career and a happy family, $99 \%$ of women would choose the latter. Women must have to maintain balance between the responsibilities of their work and their family; this leads women always to be afraid of their identity at their work. If these women want to be good wives and mothers, they believe they would not be able to lead a fruitful career.

Women's carrier in science and engineering technology is not a problem now a day's. Several good opportunities openly available in the IT industry. Now due to the better awareness more ratio of the women divert towards the IT industry/ market, they set their carrier/ goal in the field of Computer Science and Engineering. Women's prove to be better person in some areas of Information \& Technology and Computer Science Specially, as some aspects like drive for achievement, goal oriented, having passion towards their work, strong determination identified in women.

However, if organizations provide the women with female-focused policies, challenges to fascinate their personal effort for achievement and different ways of promoting their success, they can motivate women to remain in male-dominated work place.

\section{References}

Acdalal (2011). The Importance of Language and Framing, Part Eleventy-Thousand; Computer Science Gender and Diversity, http://acdalal.wordpress.com/2011/07/ 26/the-importance-of-language-and-framing-part-eleventy-thousand/

Ayse, Bugra (2014). Revisiting the Wollstonecraft Dilemma in the Context of Conservative Liberalism: The Case of Female Employment in Turkey, Social Politics, vol. 21, No (1), pp. 148-166. 
Day, J.C. \& Newburger, E. C. (2002). The Big Pay Off: Educational Attainment and Synthetic Estimates of Work-life Earnings, ERIC Clearinghouse on Adult, Career, and Vocational Education, Ohio: Columbus.

Graham, J.W., \& Smith, S.A (2005). Gender Differences I Employment and Earnings in Science and Engineering in the U.S, Economics of Education Review, vol. 24, pp. 341-354

Judy, Bart (2000). Women Succeeding in the Sciences: Theories and Practices Across Disciplines: Purdue University Press e-books, 6-15-2000.

Justin, T Denney et.al (2013). Families, Resources, and Adult Health where do Sexual Minorities Fir?, Journal of Health and Social Behavior: SAGE.

Mark, J. Cherry (2010). Parental Authority and Pediatric Bioethical Decision Making, The Journal of Medicine \& Philosophy, vol. 35 (5) pp. 553-572

Pearl, Amy et.al (1990). Becoming a Computer Scientist A Report by the ACM Committee on the Status of Women in Computing Science, Communications of the ACM, pp. 48-57.

Richard, M. Feilder \& Rebecca, Brent (2005). Understanding Student Differences, Journal of Engineering Education, 94(1), 57-72

Tinklin, T., Croxford, L., Ducklin, A. \& Frame, B. (2005). Gender Attitudes to Work and Family Roles: The Views of Young People at the Millennium, Gender and Education, 17, pp. 129-142.

Weisert, Conrad. (2014). Women Programmers of the Past and Present, http://www.idinews.com/women1959.html

Dr. M. Sadiq Ali Khan is Assistant Professor in the Department of Computer Science, University of Karachi.

Dr. Muhammad Nadeemullah is Assistant Professor in the Department of Social Work, University of Karachi.

Ghazal Khwaja Humayyun Akhtar is Assistant Professor in the Department of Public Administration, University of Karachi. 